\title{
Adaptive Speed Identification Air-gap Flux Vector-controlled Induction Motor Drive Based on Firefly Algorithm
}

\author{
Yung-Chang Luo, ${ }^{*}$ Yan-Chen Ji, Chia-Hung Lin, and Wen-Cheng Pu \\ Department of Electrical Engineering, National Chin-Yi University of Technology, \\ No. 57, Sec. 2, Zhongshan Rd, Taiping Dist., Taichung 41170, Taiwan (ROC)
}

(Received June 16, 2020; accepted November 7, 2020)

Keywords: speed identification, air-gap flux vector-controlled (AGFVC), model reference adaptive control (MRAC), firefly algorithm (FA)

An adaptive speed-identification scheme based on the firefly algorithm (FA) is presented for an air-gap flux vector-controlled (AGFVC) induction motor (IM) drive. The AGFVC IM drive was established using a stator current and air-gap flux. The stator current was acquired from an IM using a Hall effect sensing element. The Hall effect element was employed as an electromagnetic sensor to detect the stator current while the AGFVC IM was rotating under different reversible steady-state speed commands. Model reference adaptive control (MRAC) was utilized to develop a synchronous speed-identification scheme based on the reactive power of the motor, and the rotor speed was estimated by subtracting the slip speed from the estimated synchronous speed. The MRAC adaptation mechanism was designed using the FA. The MATLAB/Simulink ${ }^{\mathcal{O}}$ toolbox was used to simulate the proposed AGFVC IM drive system, and all the control algorithms were implemented using a TI DSP 6712-and-F2812 control card to generate pulse width modulation signals through the power stage to actuate the motor. Both simulation and experimental results verified the effectiveness of the proposed system.

\section{Introduction}

Intelligent manufacturing requires numerous high-performance motor drives to actuate appliances. Induction motors (IMs) are commonly used under their conditions as highperformance motor drives because of their robustness, low cost, low maintenance, and suitability in hostile environments. However, IM control is more difficult than DC motor control because the mathematical model of IM control is nonlinear, coupled, and time-variant. In accordance with the flux vector control (FVC) principle of IMs, ${ }^{(1)}$ the complicated mathematical model of IMs can be transformed into torque-current and flux-current components via coordinate transformation. Both components are orthogonal and can be separately controlled, thus allowing the attainment of the maximum torque-to-current ratio. FVC IM drives are classified into rotor, stator, and air-gap types. Most studies on FVC IM drives have focused on the rotor and stator types, ${ }^{(2-5)}$ with the air-gap flux vector-controlled (AGFVC) drive receiving less attention. Developing a conventional FVC IM drive requires a speed sensor, such as a

*Corresponding author: e-mail: luoyc@ncut.edu.tw https://doi.org/10.18494/SAM.2021.3018 
digital encoder or an analog resolver, to detect the shaft position. However, this sensor reduces the IM robustness and is unsuitable for hostile environments. Hence, the development of speed-identification schemes to replace the shaft position sensor is required. Several speedidentification schemes of FVC IMs have been published, including speed adjustment through an extended Kalman filter ${ }^{(6-8)}$ speed estimation derived from an adaptive control system scheme, ${ }^{(9,10)}$ speed determination according to a flux estimator or the electromotive force of an $\mathrm{IM}^{(11-13)}$ and speed estimation from a neural network or fuzzy logic control. ${ }^{(14,15)}$ In this study, model reference adaptive control (MRAC) was utilized to develop a synchronous speedidentification scheme based on the reactive power of an IM, and the estimated rotor speed was obtained by subtracting the slip speed from the estimated synchronous speed. The firefly algorithm (FA) was used to design an adaptation mechanism of MRAC because it has rapid convergence and is suitable for various conditions. Compared with the abovementioned speedidentification schemes, this scheme has the advantages of adaptability, structural simplicity, and ease of implementation. Hall effect current sensors were used to measure the IM stator current during the implementation of this speed-identification adaptive AGFVC IM drive.

This paper is divided into sections as follows. Section 1 presents the research background, motivation, and a literature review on the speed-identification methods for FVC IM drives. Section 2 discusses the decoupled AGFVC IM drive system used in this study. Section 3 describes the MRAC synchronous speed-identification scheme based on the reactive power of an IM. Section 4 describes the design of an MRAC adaptation mechanism using the FA. Section 5 gives experiment results and a discussion, and the conclusions are presented in Sect. 6.

\section{Establishment of AGFVC IM Drive}

The vector state equations of an IM expressed in terms of the stator current and the air-gap flux in the synchronous reference coordinate frame are given by ${ }^{(16)}$

$$
\begin{gathered}
p \vec{i}_{s}^{e}=\frac{1}{L_{\lambda}}\left(L_{r} R_{s}-L_{m} R_{r}+j \omega_{e} L_{r} L_{s l}-j \omega_{s l} L_{m} L_{r l}\right) \vec{i}_{s}^{e}+\frac{1}{L_{\lambda}}\left(R_{r}-j \omega_{r} L_{r}\right) \vec{\lambda}_{a g}^{e}+\frac{L_{r}}{L_{\lambda}} \vec{v}_{s}^{e}, \\
p \vec{\lambda}_{a g}^{e}=\frac{1}{L_{\lambda}}\left(L_{m} L_{s l} R_{r}-L_{m} L_{r l} R_{s}-j \omega_{r} L_{m} L_{s l} L_{r l}\right) \vec{i}_{s}^{e}-\frac{1}{L_{\lambda}}\left(L_{s l} R_{r}+j \omega_{e} L_{m} L_{r l}+j \omega_{s l} L_{s l} L_{r}\right) \vec{\lambda}_{a g}^{e}+\frac{L_{m} L_{r l} \vec{v}_{s}^{e},}{L_{\lambda}}
\end{gathered}
$$

where $j$ is the imaginary unit; $\vec{v}_{s}^{e}=v_{d s}^{e}+j v_{q s}^{e}$ and $\vec{i}_{s}^{e}=i_{d s}^{e}+j i_{q s}^{e}$ are the voltage and current of the stator, $\vec{\lambda}_{a g}^{e}=\lambda_{\text {dag }}^{e}+j \lambda_{\text {qag }}^{e}$ is the air-gap flux; $R_{S}$ and $R_{r}$ are the stator and rotor resistances; $L_{S}$, $L_{r}$, and $L_{m}$ are the stator, rotor, and mutual inductances; $L_{s l}=L_{s}-L_{m}$ and $L_{r l}=L_{r}-L_{m}$ are the stator and rotor leakage inductances, respectively; $L_{\lambda}=L_{m} L_{r l}+L_{r} L_{s l} ; \omega_{e}$ is the speed of the synchronous reference coordinate frame; $\omega_{r}$ is the speed of the rotor; $\omega_{s l}=\omega_{e}-\omega_{r}$ is the slip speed; and $p$ is the differential operator.

Under an AGFVC condition and with $\lambda_{q a g}^{e}=0$ set in Eqs. (1) and (2), the estimated slip speed and the $d$-axis air-gap flux are derived as 


$$
\begin{gathered}
\hat{\omega}_{s l}=\frac{\left(\left(L_{r l} / R_{r}\right) s+1\right) i_{q s}^{e}}{\left(\tau_{r} / L_{m}\right) \lambda_{d a g}^{e}-\left(L_{r l} / R_{r}\right) i_{d s}^{e}}, \\
\frac{\tau_{r} s+1}{\left(L_{r l} / R_{r}\right) s+1} \frac{\lambda_{d a g}^{e}}{L_{m}}=i_{d s}^{e}-\frac{\hat{\omega}_{s l} L_{r l} / R_{r}}{\left(L_{r l} / R_{r}\right) s+1} i_{q s}^{e},
\end{gathered}
$$

where the symbol $\wedge$ indicates an estimated value and $s$ is the Laplace operator.

The second term on the right side of Eq. (4) is a coupling component in relation to the $q$-axis stator current. Using this term, the $d$-axis stator current feed-forward compensation can be defined as

$$
i_{d s_{-} c o m p}^{e}=\frac{\hat{\omega}_{s l} L_{r l} / R_{r}}{\left(L_{r l} / R_{r}\right) s+1} i_{q s}^{e} .
$$

This compensation $i_{d s}^{e}$ comp is placed on the output of the $d$-axis stator current control loop. Hence, the linear control relationship between the $d$-axis air-gap flux and $d$-axis stator current can be derived as

$$
\lambda_{\text {dag }}^{e}=\frac{\left(L_{r l} / R_{r}\right) s+1}{\tau_{r} s+1} L_{m} i_{d s}^{e} .
$$

The developed electromagnetic torque of an IM under an AGFVC condition is given by

$$
T_{e}=\frac{3 P}{4} i_{q s}^{e} \lambda_{\text {dag }}^{e}
$$

where $P$ is the motor pole number. $i_{q s}^{e}$ and $\lambda_{d a g}^{e}$ are orthogonal in Eq. (7) and can be separately controlled. The developed electromagnetic torque of an IM is dominated by $i_{q s}^{e}$, and the maximum torque-to-current ratio can be attained under an AGFVC condition. The mechanical equation of the motor is acquired as

$$
J_{m} p \omega_{r m}+B_{m} \omega_{r m}+T_{L}=T_{e},
$$

where $J_{m}$ and $B_{m}$ are the inertial and viscous friction coefficients of the motor, respectively; $T_{L}$ is the load torque; and $\omega_{r m}=(2 / P) \omega_{r}$ is the mechanical speed of the motor shaft.

Furthermore, with $\lambda_{q a g}^{e}=0$ set in Eqs. (1) and (2), the $d$-axis and $q$-axis stator voltage equations under an AGFVC condition are respectively obtained from

$$
\begin{gathered}
\left(R_{s}+L_{s l} p\right) i_{d s}^{e}-\omega_{e} L_{s l} l_{q s}^{e}+p \lambda_{d a g}^{e}=v_{d s}^{e}, \\
\left(R_{s}+L_{s l} p\right) i_{q s}^{e}+\omega_{e} L_{s l} i_{d s}^{e}+\omega_{e} \lambda_{d a g}^{e}=v_{q s}^{e} .
\end{gathered}
$$


An inspection of Eq. (9) shows that the second and third terms on the left side are the coupling components in relation to the $q$-axis stator current and $d$-axis air-gap flux, respectively. Furthermore, an inspection of Eq. (10) shows that the second and third terms on the left side are the coupling components in relation to the $d$-axis stator current and $d$-axis air-gap flux, respectively. By definition, the $d$-axis and $q$-axis stator voltage feed-forward compensations are expressed as

$$
\begin{gathered}
v_{d s_{-} \text {comp }}^{e}=-\omega_{e} L_{s l} l_{q s}^{e}+p \lambda_{d a g}^{e}, \\
v_{q s_{-} c o m p}^{e}=\omega_{e} L_{s l} l_{d s}^{e}+\omega_{e} \lambda_{d a g}^{e} .
\end{gathered}
$$

The linear relationships of the $d$-axis and $q$-axis stator current control loops are thus obtained.

The voltage commands of the $d$-axis and $q$-axis stator current control loops are given by

$$
\begin{aligned}
& v_{d s}^{e^{*}}=v_{d s}^{e^{\prime}}+v_{d s_{-}}^{e} \text { comp }, \\
& v_{q s}^{e^{*}}=v_{q s^{\prime}}^{e^{\prime}}+v_{q s_{-} \text {comp }}^{e},
\end{aligned}
$$

where $v_{d s}^{e^{\prime}}$ and $v_{q s}^{e^{\prime}}$ are the outputs of the $d$-axis and $q$-axis stator current controllers, respectively. By using Eqs. (9) and (11) and Eqs. (10) and (12), the plants of the $d$-axis and $q$-axis stator current control loops are obtained from

$$
\begin{aligned}
& G_{p_{-} i_{d s}}(s)=\frac{1}{R_{s}+L_{s l} s}, \\
& G_{p_{-} i_{q s}}(s)=\frac{1}{R_{S}+L_{s l} s} .
\end{aligned}
$$

Given that the bandwidths of the stator current control loops are much higher than those of the flux and speed control loops, the closed-loop gain of the stator current control loops can be regarded as a unity. ${ }^{(17)}$ In accordance with Eqs. (6) and (8), the plants of the flux control loop and the speed control loop are obtained from

$$
\begin{gathered}
G_{p_{-} f l u x}(s)=\frac{1+\left(L_{r l} / R_{r}\right) s}{1+\tau_{r} s} L_{m}, \\
G_{p_{-} \text {speed }}(s)=\frac{1}{B_{m}+J_{m} s} .
\end{gathered}
$$




\section{MRAC Synchronous Speed-identification Scheme}

The feedback speed signal is replaced by an estimated speed in the speed-identification AGFVC IM drive, and this estimated speed can be derived using the designed MRAC synchronous speed-identification scheme based on the reactive power of an IM. The $d$-axis and $q$-axis stator voltages in the synchronous reference coordinate frame are obtained as follows:

$$
\begin{aligned}
& v_{d s}^{e}=\left(R_{s}+L_{s l} p\right) i_{d s}^{e}-\omega_{e} L_{s l} l_{q s}^{e}+p \lambda_{d a g}^{e}-\omega_{e} \lambda_{q a g}^{e}, \\
& v_{q s}^{e}=\left(R_{s}+L_{s l} p\right) i_{q s}^{e}+\omega_{e} L_{s l} l_{d s}^{e}+p \lambda_{q a g}^{e}+\omega_{e} \lambda_{d a g}^{e} .
\end{aligned}
$$

The reactive power of an IM acquired from the power source can be expressed as

$$
Q=v_{q s}^{e} i_{d s}^{e}-v_{d s}^{e} i_{q s}^{e}
$$

By substituting Eqs. (19) and (20) into Eq. (21) and setting $\lambda_{\text {qag }}=$, the reactive power of an IM under the AGFVC condition can be expressed as

$$
Q^{\prime}=\hat{\omega}_{e}\left(L_{s l}\left(\left(i_{d s}^{e}\right)^{2}+\left(i_{q s}^{e}\right)^{2}\right)+\lambda_{d a g}^{e} i_{d s}^{e}\right)-i_{q s}^{e} p \lambda_{d a g}^{e}
$$

According to the MRAC theory, ${ }^{(17)}$ Eq. $(21)$ can be selected as the reference model because it does not contain the estimated synchronous speed $\hat{\omega}_{e}$. Given that Eq. (22) contains $\hat{\omega}_{e}$, it can be selected as the adjustable model. The difference between the reference model and the adjustable model is fed to an adaptation mechanism to identify $\hat{\omega}_{e}$. The proposed MRAC synchronous speed-identification scheme is shown in Fig. 1. The adaptation mechanism of this scheme was designed using the FA. Here, the stator current is measured from an IM using Hall effect current sensors.

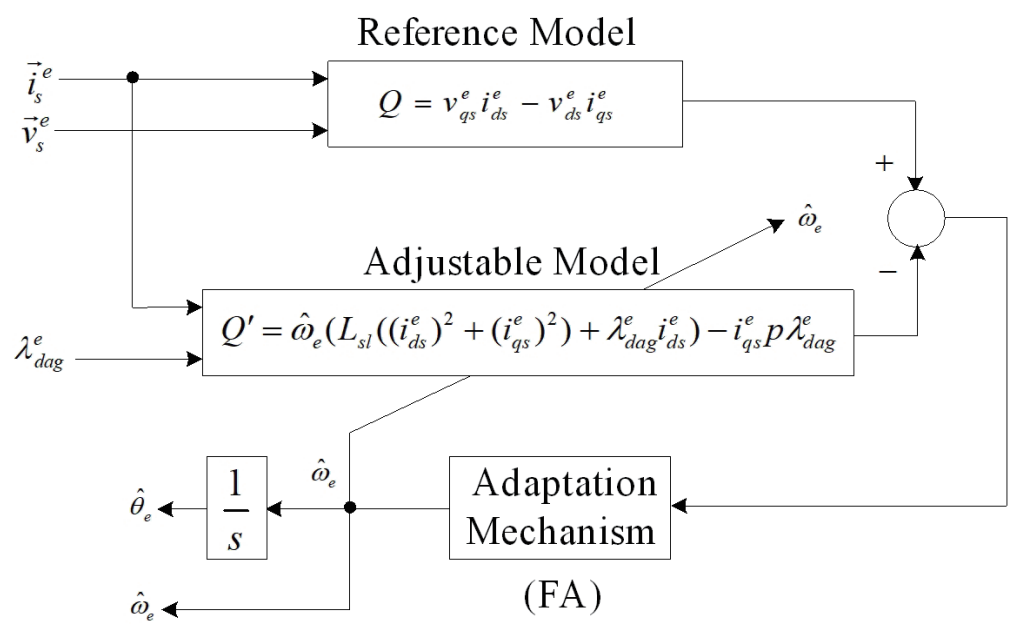

Fig. 1. MRAC synchronous speed-identification based on the reactive power of an IM. 
In accordance with Fig. 1 and by using Eq. (3), the estimated rotor speed is acquired as

$$
\hat{\omega}_{r}=\hat{\omega}_{e}-\hat{\omega}_{s l}
$$

Furthermore, the estimated synchronous position angle for implementing a coordinate transformation between the synchronous and stationary reference coordinate frames is given by

$$
\hat{\theta}_{e}=\frac{1}{s} \cdot \hat{\omega}_{e}
$$

\section{MRAC Adaptation Mechanism Design Using FA}

Swarm intelligence algorithms, such as the particle swarm optimization algorithm, wolf pack search algorithm, artificial fish school algorithm, and $F A,{ }^{(18,19)}$ have been utilized to identify the controller parameters of the adaptation mechanism. These algorithms simulate the biotic habitual behavior of birds, fish, or fireflies to solve optimization problems and search for global optimal solutions through iterative computations. In other words, the algorithms are optimal for solving mathematical problems. Swarm intelligence algorithms are different from genetic inheritance algorithms, which do not require the crossover and mutation processes. In a swarm optimization search, each individual is provided with intelligence (memory); the search is guided toward the best solution in accordance with the individual learning experience or the best learning experiences among the swarm; that is, the individual and swarm learning experiences are combined. The search can be realized by the communication of learning experiences between individuals and the swarm. The conditions of interaction and containment occur among these individuals, resulting in a global search that continuously approaches the desired target.

In the FA, multiple fireflies are randomly generated in the search space with positions, $a_{n}, n=1,2, \ldots, N$, such as $a_{n}^{i}$ is the current position at the $i$ th search stage; $N$ is the number of firefly agents, which can search for the optimal solution from $N$ directions at each search stage; $i=1,2, \ldots, i_{\max }$ is the iteration number; and $i_{\max }$ is the maximum number of iteration computations. Each firefly carrying a luminescence quality is attracted to adjacent brighter fireflies, as attractiveness $\delta\left(r_{n}\right)$ decreases with the increase in the Cartesian distance $r_{n}$. Attractiveness is proportional to the firefly brightness, and a firefly with less brightness moves toward a brighter one.

- To search for a brighter firefly, the following equations are used:

$$
\begin{gathered}
r_{n}=\left\|a_{\text {best }}-a_{n}^{i}\right\|=\sqrt{\left(a_{\text {best }}-a_{n}^{i}\right)^{2}}, n=1,2, \ldots, N, \\
\delta\left(r_{n}\right)=\delta_{0} \exp \left(-\gamma r_{n}^{2}\right) .
\end{gathered}
$$


When the Cartesian distance $r_{n}$ approaches zero, two fireflies attract each other and have the same brightness (possessing the maximum attraction $\delta_{0}$ ); otherwise, $r_{n} \rightarrow \infty$, and the attraction between the two fireflies approaches zero $\left(\delta\left(r_{n}\right) \rightarrow 0\right)$, and therefore, communication cannot occur between the two fireflies. In Eq. (26), $\gamma$ is the light absorption coefficient.

Suppose $a_{\text {best }}$ is a firefly brighter than any other firefly $a_{n}^{i}$ at the $i$ th iteration computation; then, firefly $a_{n}^{i}$ moves to a new position.

- The position of the firefly is updated as follows:

$$
a_{n}^{i+1}=a_{n}^{i}+\delta(r)\left(a_{\text {best }}-a_{n}^{i}\right)+\alpha(\text { rand }-0.5),
$$

where the second term is the attraction of firefly $a_{b e s t}$ to the adjacent firefly $a_{n}^{i}$; the third term is the randomization of the movement with the randomization parameter $\alpha \in[0,1]$; and rand is the randomization parameter from a Gaussian distribution rand $\in[0,1]$. Parameters $\beta_{0}=1$ and $\gamma=1$ are used in this study, as recommended in the literature. ${ }^{(18,19)}$ The third term on the right of Eq. (27) is the random flight concept, which reduces the probability of the algorithm falling into a local solution during the solving process and promotes the solving efficacy. A flow chart of the proposed FA adaptation mechanism is shown in Fig. 2.

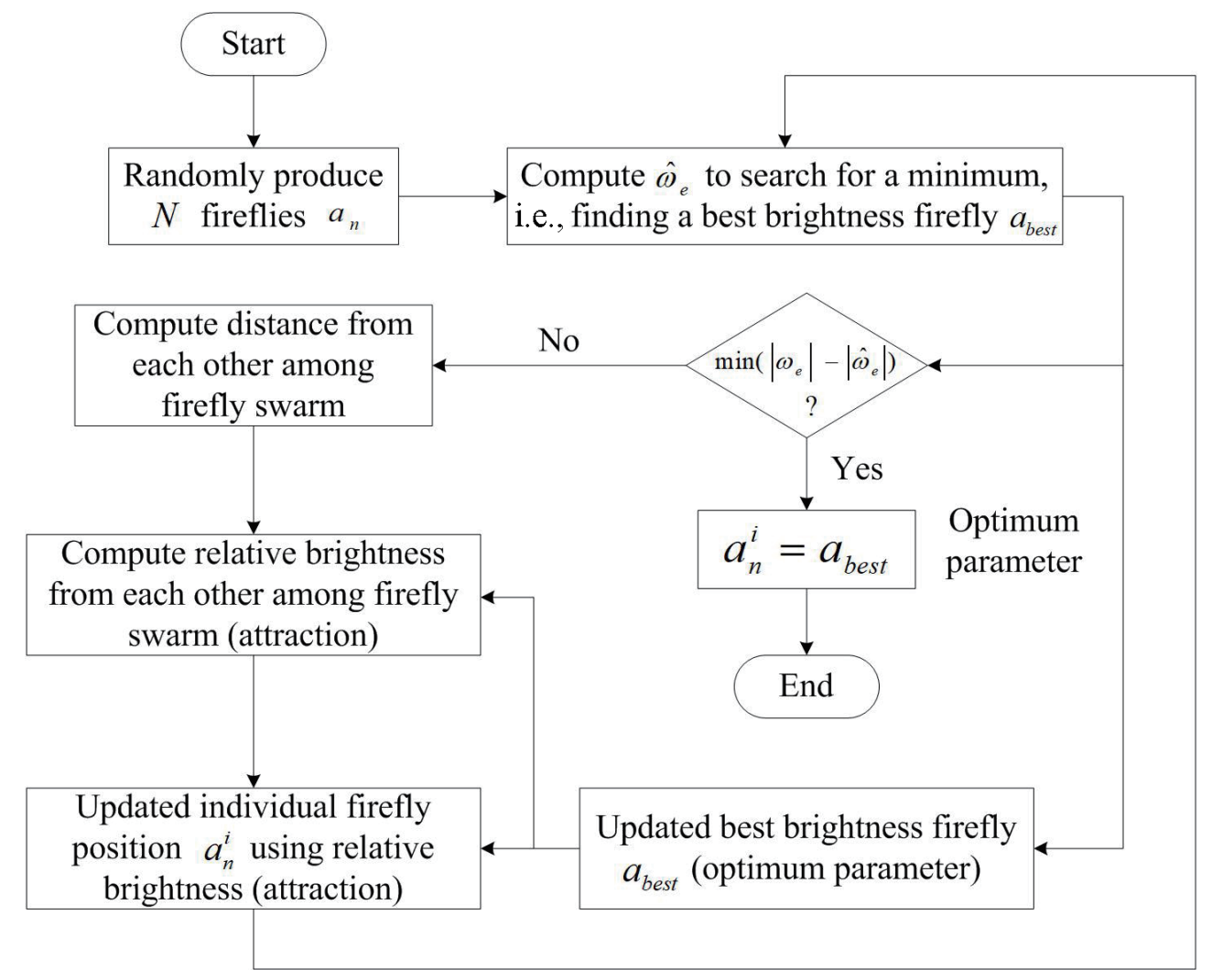

Fig. 2. Flow chart of the proposed FA adaptation mechanism design. 


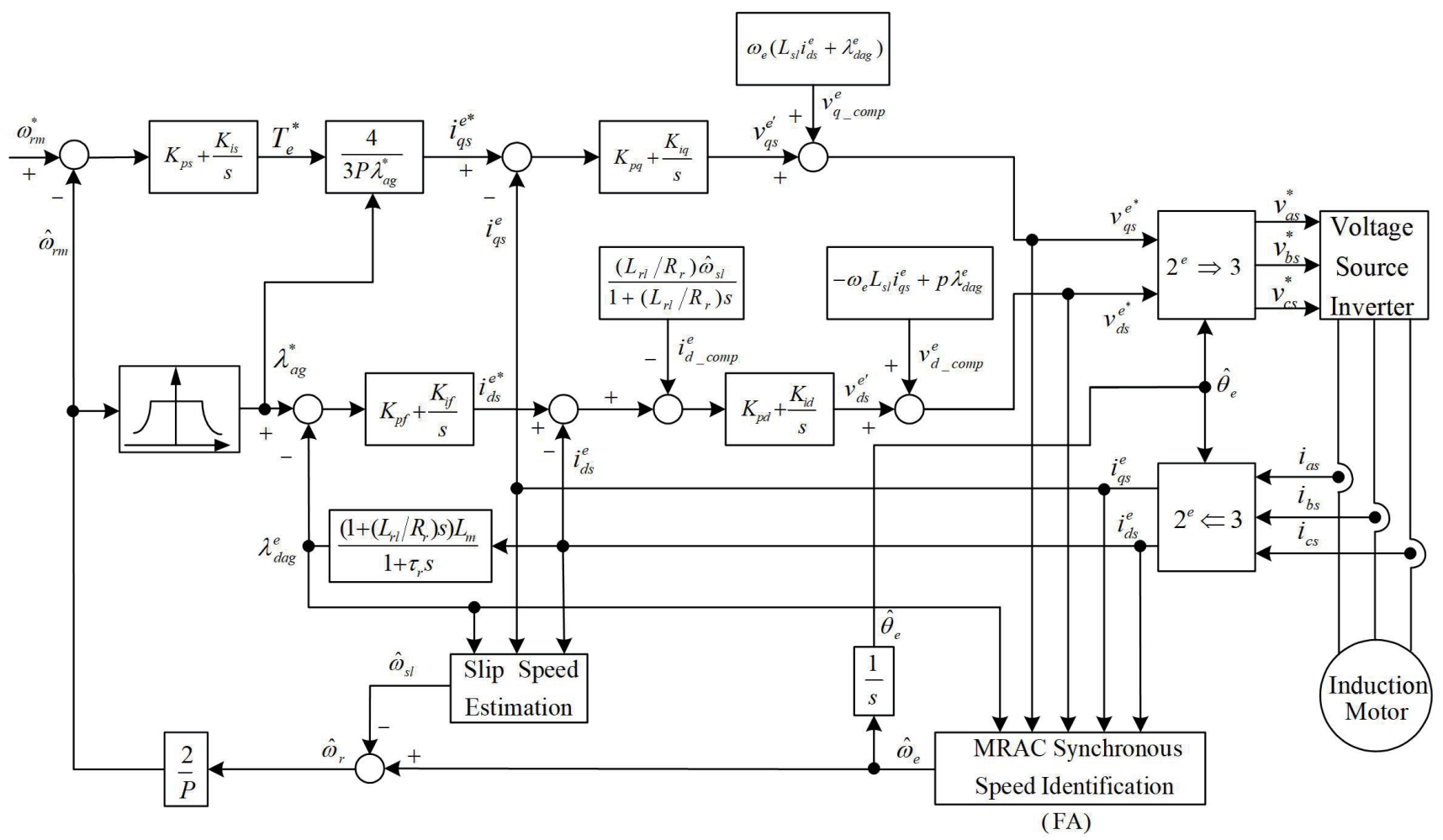

Fig. 3. Adaptive speed-identification AGFVC IM drive based on FA.

A block diagram of the proposed adaptive speed-estimation AGFVC IM drive based on the FA is shown in Fig. 3; the drive includes a speed controller, flux controller, $q$-axis and $d$-axis stator-current controllers, slip speed estimation, $d$-axis air-gap flux estimation, $d$-axis stator current feed-forward compensation, $d$-axis and $q$-axis stator voltage feed-forward compensation, coordinate transformation, and an MRAC estimation rotor speed design based on the FA.

In this system, the proportion-integral (P-I)-type controllers for the speed, flux, and $d$-axis and $q$-axis stator-current control loops were designed using the root-locus method. The adaptation mechanism of the MRAC-identified synchronous speed was designed using the FA.

\section{Experimental Results and Discussion}

A simulation scheme of the proposed AGFVC IM drive system was established using the MATLAB/Simulink ${ }^{(}$toolbox, where the implementation program was executed by a Texas Instruments DSP 6713-and-F2812 control card and a power stage to actuate the IM. A standard three-phase, $220 \mathrm{~V}, 0.75 \mathrm{~kW}, \Delta$-connected, squirrel-cage IM was used to confirm the effectiveness of the proposed adaptive speed-identification AGFVC IM drive using the FA. In a running cycle, the sequence of speed commands was designed as follows: forward-direction acceleration from $t=0 \mathrm{~s}$ to $t=1 \mathrm{~s}$; forward-direction steady-state running over $1 \leq t \leq 2 \mathrm{~s}$; forward-direction braking to reach zero speed in the interval $2 \leq t \leq 3 \mathrm{~s}$; reverse-direction 
acceleration from $t=3 \mathrm{~s}$ to $t=4 \mathrm{~s}$; reverse-direction steady-state running over $4 \leq t \leq 5 \mathrm{~s}$; reverse-direction braking to reach zero speed in the interval $5 \leq t \leq 6 \mathrm{~s}$.

The simulation and experiment results of the proposed adaptive speed-identification AGFVC IM drive using the FA are depicted in Figs. 4-7. Each figure includes six responses: (a) command (dashed line) and estimated (solid line) rotor speed, (b) command (dashed line) and actual (solid line) rotor speed, (c) electromagnetic torque, (d) stator current, (e) air-gap flux position angle, and (f) air-gap flux locus ( $q$-axis vs $d$-axis). The simulation and experimental results with a $2 \mathrm{~N}-\mathrm{m}$ load for reversible steady-state speed commands of 200 and $1800 \mathrm{rev} / \mathrm{min}$ are shown in Figs. 4 and 5 and Figs. 6 and 7, respectively.

According to the results of the simulated and experimental tests in different reversible transient and steady-state operations, the developed MRAC speed-identification scheme based on the FA adaptation mechanism can accurately estimate different rotor speeds (reversible steady-state commands: 200 and $1800 \mathrm{rev} / \mathrm{min}$ ) under a load condition. Furthermore, as seen in subfigures (e) and (f) in Figs. 4 to 7, the sawtooth shape air-gap flux position angle and

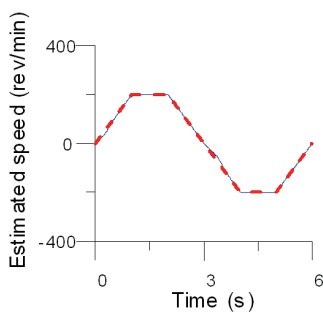

(a)

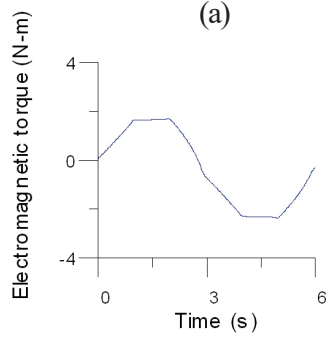

(c)

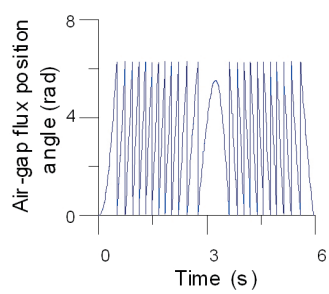

(e)

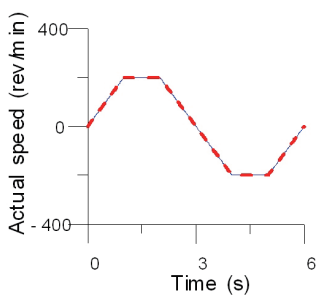

(b)

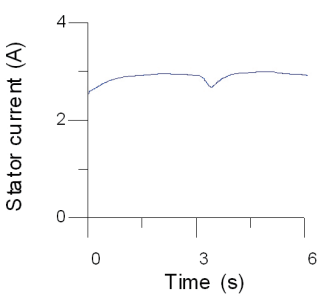

(d)

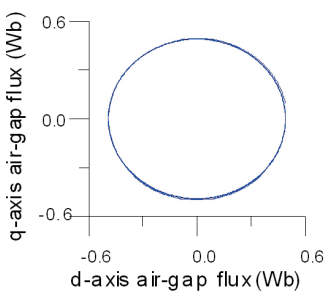

(f)

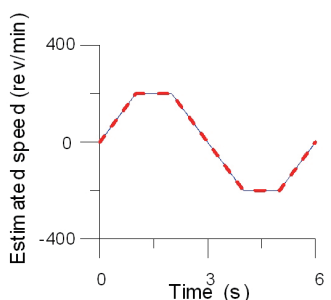

(a)

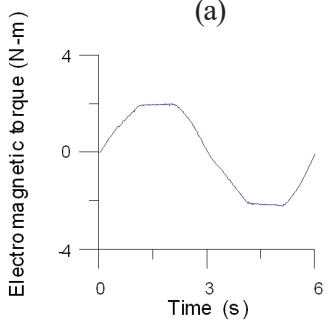

(c)

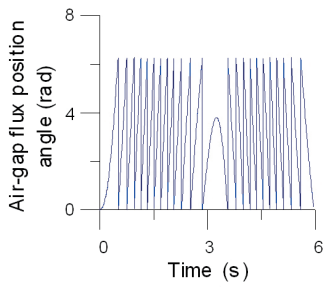

(e)

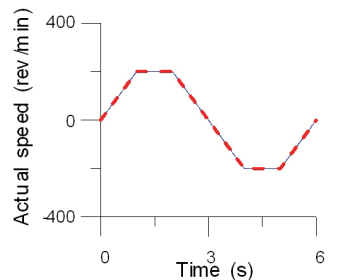

(b)

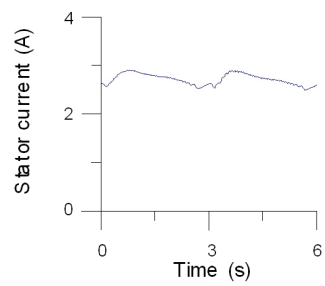

(d)

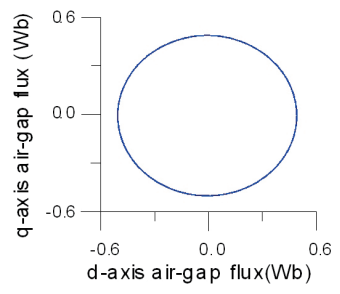

(f)

Fig. 4. (Color online) Simulated responses of the proposed adaptive speed-identification AGFVC IM drive based on FA with $2 \mathrm{~N}$-m load for reversible steady-state speed command of $200 \mathrm{rev} / \mathrm{min}$ : (a) estimated rotor speed, (b) actual rotor speed, (c) electromagnetic torque, (d) stator current, (e) air-gap flux position angle, and (f) air-gap flux locus.

Fig. 5. (Color online) Experimental responses of the proposed adaptive speed-identification AGFVC IM drive based on FA with $2 \mathrm{~N}$-m load for reversible steady-state speed command of $200 \mathrm{rev} / \mathrm{min}$ : (a) estimated rotor speed, (b) actual rotor speed, (c) electromagnetic torque, (d) stator current, (e) air-gap flux position angle, and (f) air-gap flux locus. 


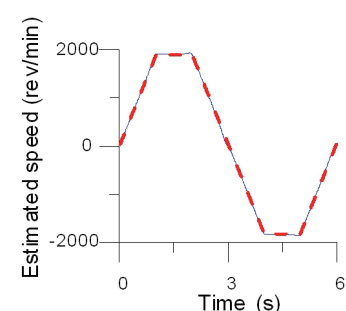

(a)

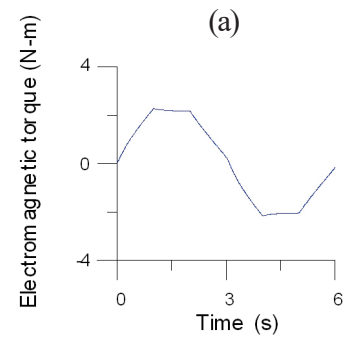

(c)

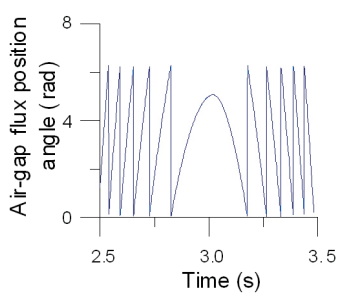

(e)

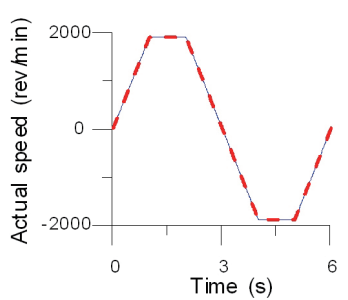

(b)

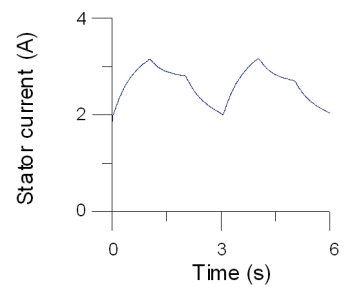

(d)

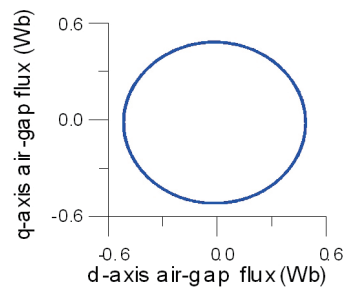

(f)

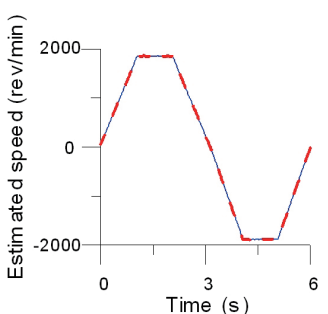

(a)

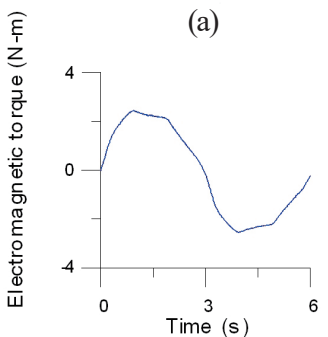

(c)

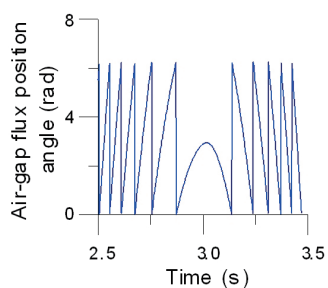

(e)

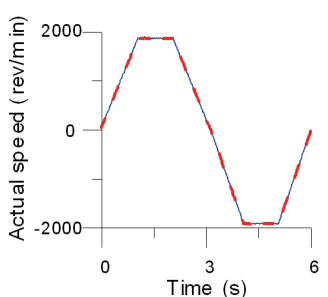

(b)

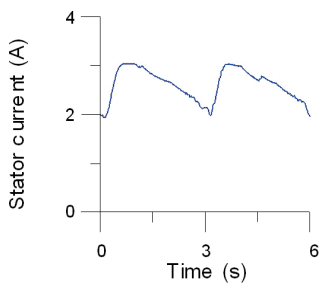

(d)

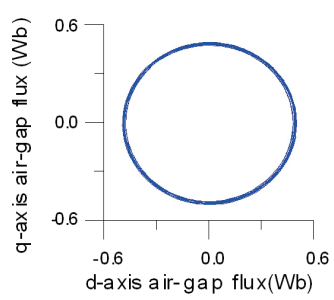

(f)

Fig. 6. (Color online) Simulated responses of the proposed adaptive speed-identification AGFVC IM drive based on FA with $2 \mathrm{~N}$-m load for reversible steady-state speed command of $1800 \mathrm{rev} / \mathrm{min}$ : (a) estimated rotor speed, (b) actual rotor speed, (c) electromagnetic torque, (d) stator current, (e) air-gap flux position angle, and (f) air-gap flux locus.

Fig. 7. (Color online) Experimental responses of the proposed adaptive speed-identification AGFVC IM drive based on FA with $2 \mathrm{~N}-\mathrm{m}$ load for reversible steady-state speed command of $1800 \mathrm{rev} / \mathrm{min}$ : (a) estimated rotor speed, (b) actual rotor speed, (c) electromagnetic torque, (d) stator current, (e) air-gap flux position angle, and (f) air-gap flux locus.

circular air-gap flux locus confirmed the exactness of the coordinate transformation. In contrast to previous studies, ${ }^{(20,21)}$ in Ref. 20 , the stator current and rotor flux were used to establish a rotor flux direct-vector-controlled IM drive. A rotor flux estimator was developed according to the model reference adaptive system (MRAS) based on the voltage-model and current-model estimated rotor fluxes, and the estimated rotor speed was derived from this rotor flux estimator. The adaptation mechanism of the MRAS rotor flux estimator was designed using a fuzzy logic control strategy. In addition, in Ref. 21, an air-gap flux observer based on the Lyapunov stability theory was developed, and the estimated rotor speed was acquired from this air-gap flux observer. The observer gain matrix of the air-gap flux observer was designed using the particle swarm optimization algorithm. In this study, an AGFVC IM drive was established using the stator current and air-gap flux. A synchronous speed-identification scheme was developed according to MRAC based on the reactive power, and the estimated rotor speed was obtained by subtracting the estimated slip speed from the estimated synchronous speed. In adaptive synchronous speed estimation, the adaptation mechanism of the RAC synchronous speedidentification scheme was designed using the FA. 


\section{Conclusions}

A speed-identification AGFVC IM drive was established using an FA-based MRAC adaptation mechanism. The air-gap flux and stator current were used to develop a decoupled AGFVC IM model. An MRAC synchronous speed-identification scheme based on the reactive power of an IM was developed, and the rotor speed was estimated by subtracting the slip speed from the estimated synchronous speed. The adaptation mechanism of the MRAC was designed using the FA. The stator current signal measurement for implementing the adaptive speedidentification AGFVC IM drive was provided by Hall effect current sensors. Both the simulation and experimental results for different reversible steady-state speed commands under a load condition verified the promising performance of the proposed adaptive speed-identification AGFVC IM drive.

\section{References}

1 Y. C. Luo, B. W. Chen, W. C. Pu, and N. S. Pai: Sens. Mater. 32 (2020) 239. https://doi.org/10.18494/ SAM.2020.2574

2 S. Yang, D. Ding, X. Li, Z. Xie, X. Zhang, and L. A. Chang: IEEE Trans. Energy. Conv. 32 (2017) 1562. https://doi.org/10.1109/TEC.2017.2699681

3 S. Bozhko, S. Dymko, S. Kovbasa, and S. M. Peresada: IEEE Trans. Ind. Appl. 53 (2017) 181. https://doi. org/10.1109/TIA.2016.2608789

4 A. K. Abdelsalam, M. I. Masoud, M. S. Hamad, and B. W. Williams: IEEE Trans. Ind. Appl. 48 (2012) 2433. https://doi.org/10.1109/TIA.2012.2227132

5 G. C. Konstantopoulos, A. T. Alexandridis, and E. D. Mitronikas: IEEE Trans. Control. Syst. Technol. 22 (2014) 1112. https://doi.org/10.1109/TCST.2013.2271256

6 S. Xingfa, N. Ziling, Z. Junjie, H. Yi, Y. Weiwei, S. Jun, and W. Yanhao: Proc. CSAA/IET Int. Conf. Aircraft Utility Systems (AUS 2018) 769-775. https://doi.org/10.1049/cp.2018.0136

7 M. Farasat, A. M. Trzynadlowski, and M. S Fadali: IET J. Electron. Syst. Transportation 4 (2014) 122. https:// doi.org/10.1049/iet-est.2014.0018

8 M. Farasat, E. Karaman, A. M. Trzynadlowski, and M. S. Fadali: Proc. 2012 IEEE Energytech (IEEE 2012) 1-6. https://doi.org/10.1109/10.1109/EnergyTech.2012.6304634

9 M. S. Morey, V. B. Virulkar, and G. A. Dhomane: Proc. 2016 Int. Conf. Electrical, Electronics, and Optimization Techniques (ICEEOT 2016) 3422-3427. https://doi.org/10.1109/ICEEOT.2016.7755340

10 M. S. Morey, V. B. Virulkar, and G.A. Dhomane: Proc. 2016 Int. Conf. Emerging Trends in Electrical Electronics \& Sustainable Energy Systems (ICETEESES 2016) 179-185. https://doi.org/10.1109/ ICETEESES.2016.7581381

11 D. D. Pinheiro, G. M. O Stein, J. P. Costa, R. Cardoso, and E. G. Carati: Proc. 2015 IEEE 13th Brazilian Power Electronics Conf. and 1st Southern Power Electronics Conf. (COBEP/SPEC 2015) 1-6. https://doi.org/10.1109/ COBEP.2015.7420106

12 Y. C. Luo and C. L. Tsai: Low Freq. Noise Vib. Act. Control 38 (2019) 1220. https://doi. org/10.1177/1461348418784187

13 M. Comanescu: Proc. 2015 9th Int. Conf. Compatibility and Power Electronics (CPE 2015) 224-229. https:// doi.org/10.1109/CPE.2015.7231077

14 Y. Sayouti, A. Abbou, M. Akherraz, and H. Mahmoudi: Proc. 2011 Int. Conf. Power Engineering, Energy and Electrical Drives (2011) 1-5. https://doi.org/10.1109/PowerEng.2011.6036501

15 Z. Boussada, M. B. Hamed, and L. Sbita: Proc. 2014 Int. Conf. Electrical Sciences and Technologies in Maghreb (CISTEM 2014) 1-5. https://doi.org/10.1109/CISTEM.2014.7077071

16 Y. C. Luo and Y. H. Chen: Intell. Fuzzy Syst. 36 (2019) 1215. https://doi.org/10.1177/1461348418824942

17 Y. C. Luo, S. H. Pei, Y. P. Kuo, and C. T. Tsai: Sens. Mater. 32 (2020) 1851. https://doi.org/10.18494/ SAM.2020.2480

18 X. S. Yang: Firefly Algorithms Formultimodal Optimization in Stochastic Algorithms: Foundations and Applications, O. Watanabe and T. Zeugmann, Eds., 5792 (Springer, Berlin, Germany, 2009) p. 169. 
19 X. S. Yang, S. S. S. Hosseini, and A. H. Gandomi: Appl. Soft Comp. 12 (2012) 1180. https://doi.org/10.1016/ j.asoc.2011.09.017

20 Y. P. Kuo and Y. C. Ji: Low Freq. Noise Vib. Act. Contr. 2019 (2019) 1. https://doi. org $/ 10.1177 / 1461348419842694$

21 Y. C. Luo, Y. H. Chen, and W.C. Pu: Proc. 2018 Int. Symp. Computer, Consumer and Control (IS3C 2018) 213-216. https://doi.org/10.1109/IS3C.2018.00061 